\title{
Reconfigurable Compact Spider Microstrip Antenna with New Defected Ground Structure
}

\author{
R. S. Ghoname \\ Asst. Professor at Electronics \\ Research Institute \\ Cairo, Egypt
}

\author{
M. A. Mohamed \\ MSc at Ain Shams University \\ Cairo, Egypt
}

\author{
A. EL. Hennawy \\ Professor at Ain Shams \\ University
}

\begin{abstract}
Two novel Defected Ground Structures (DGS) were first proposed, which have better results than that of the dumbbell (published shape). Using the general model of DGS, its equivalent parameters were extracted. The two new proposed shapes of DGS were then used to design a novel compact spider microstrip antenna to minimize its area. The size of the developed antenna was reduced to about $90.5 \%$ of that of the conventional one. This antenna with two different novel shapes of DGS was designed and simulated by using the ready-made software package Zeland-IE3D. Finally, it was fabricated by using thin film and photolithographic technique and measured by using vector network analyzer. Good agreements were found between the simulated and measured results.
\end{abstract}

\section{General Terms}

Equivalent circuit model, Parameters extraction, Frequency characteristics

\section{Keywords}

DGS, compact spider microstrip antenna

\section{INTRODUCTION}

Recently, various wireless communication services have been available, which use many frequency spectrum allocations, e.g., WIMAX (Worldwide Inter operability Microwave Access), BWA (Broadband Wireless Access) and WIFI (Wireless Fidelity). For these applications, microstrip antennas are preferred because of their advantages such as low profile, light weight and easy design with multi frequency bands. However, a common disadvantage of microstrip antennas is surface wave, which is excited whenever the substrate has dielectric permittivity greater than one [1]. To suppress surface waves, several studies are conducted including defected ground structure (DGS). DGS is realized by etching the ground plane with a certain lattice shape which disturbs the current distribution of the antenna. Many shapes of DGS have been studied such as concentric ring [2], circle [3], spiral [4], dumbbells [5-8], elliptical [9] and U, V slots [10]. DGS gives an extra degree of freedom in microwave circuit design and can be used for a wide range of applications. Meanwhile, for antenna applications, DGS is mainly applied to the feeding technique. The concept of Defected Ground Structures (DGS) evolved in recent years primarily from the studies of Photonic Band Gap (PBG) structures in electromagnetics. DGS refers to some compact geometries known as a unit cell etched out as a single defect or in a periodic configuration with a small period number on the ground plane of a microwave printed circuit board. This configuration provides a feature of stopping wave propagation through the substrate over a frequency range [11].

\section{DGS DESCRIPTION and FREQUENCY CHARACTERISTICS}

A defected ground structure (DGS) for the microstrip line was proposed in [12]. The DGS unit structure can provide the bandgap characteristic in some frequency bands with only one or more unit lattices as shown in Fig.1. The equivalent-circuit parameters are extracted by using a simple circuit analysis method as shown in Fig.2. By employing the extracted parameters and circuit analysis theory, the bandgap effect for the provided defected ground unit structure can be explained. By using the derived extracted equivalent circuit model and parameters, the low-pass filter is designed and simulated.

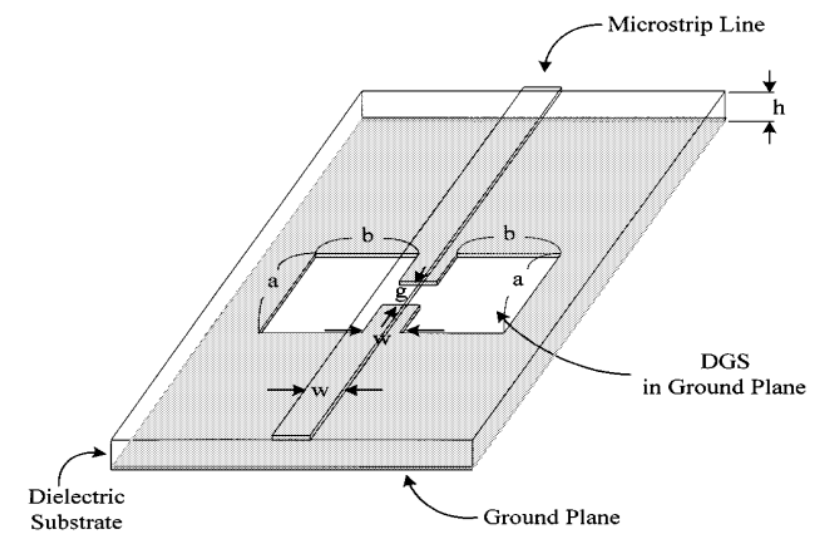

Fig: 1 Three dimensional view of the DGS unit section, which is etched in the ground plane

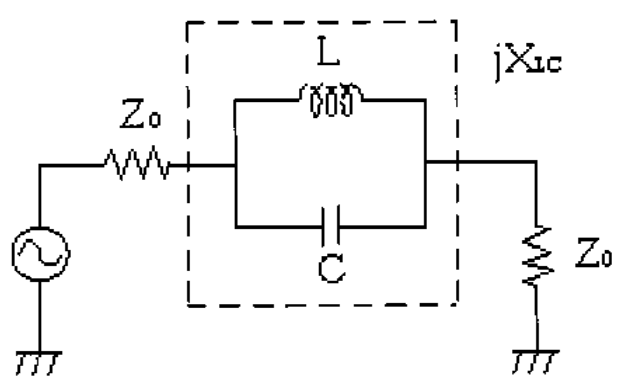

Fig: 2 Equivalent circuit of DGS unit

\subsection{Parameters extraction}

The parameters of the equivalent circuit can be obtained by using eqs. $(1,2)$ where $f_{o}$ is the attenuation pole location, $f_{c}$ is the $3-\mathrm{dB}$ cutoff frequency, $\mathrm{Z}_{\mathrm{o}}$ is the characteristic impedance and $g_{1}$ is given by the prototype value of the Butterworth-type 
low pass filter. It is found that the values of the equivalent lumped element circuit model are $0.3397 \mathrm{pF}, 9.86 \mathrm{nH}$ respectively.

$$
\begin{aligned}
& C=\frac{\omega_{G}}{Z_{0} g_{1}\left(\omega_{0}^{2}-\omega_{G}^{2}\right)} \\
& L=\frac{1}{4 \pi^{2} \mathrm{f}_{0}{ }^{2} \mathrm{C}}
\end{aligned}
$$

The lattice dimensions of the dumbbell DGS unit section were $\mathrm{a}=\mathrm{b}=12 \mathrm{~mm}$ and the gap distance $\mathrm{g}=0.6 \mathrm{~mm}$ by using FR-4 substrate material with thickness $\mathrm{h}=1.6 \mathrm{~mm}$, dielectric constant $\varepsilon_{\mathrm{r}}=4.65$ and tangent loss $(\tan \delta=0.02)$. The extracted equivalent circuit parameters for the dumbbell DGS unit section is illustrated in Table 1 and the simulating result is shown in Fig. 3 respectively.

Table 1. Extracted equivalent circuit parameters for the DGS section

\begin{tabular}{|c|l|l|l|l|l|}
\hline DGS & DGS & $\mathbf{F}_{\mathrm{o}}$ & $\mathbf{F}_{\mathrm{c}}$ & \multicolumn{1}{c|}{$\mathbf{C}$} & $\mathbf{L}(\mathrm{nH})$ \\
& $\begin{array}{l}\text { Area } \\
(\mathrm{GHz})\end{array}$ & $(\mathrm{GHz})$ & $(\mathrm{pF})$ & \\
& $\left(\mathrm{mm}^{2}\right)$ & & & & \\
\hline & 336 & $\approx 2.75$ & $\approx 1.27$ & $\approx 0.3397$ & $\approx 9.86$ \\
\hline & & & & & \\
\hline
\end{tabular}

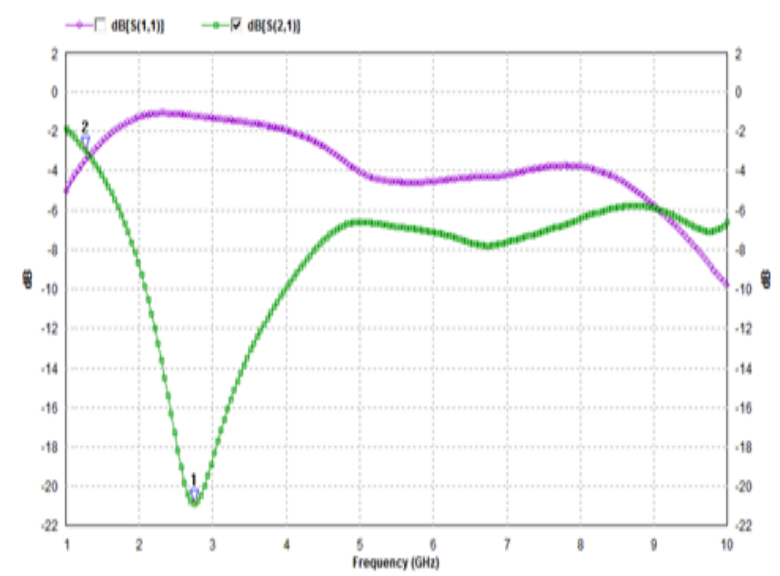

Fig: 3 Frequency response simulation of dumbbell-shape DGS

\subsection{Novel DGS Shapes Description and \\ Frequency Characteristics}

We suggest two novel DGS (N-shape, Meander-shape) as shown in Fig. 4(a, b respectively) with total area $4 \lambda \mathrm{g}$. Simulated frequency responses are shown in Fig. 5(a, b respectively).

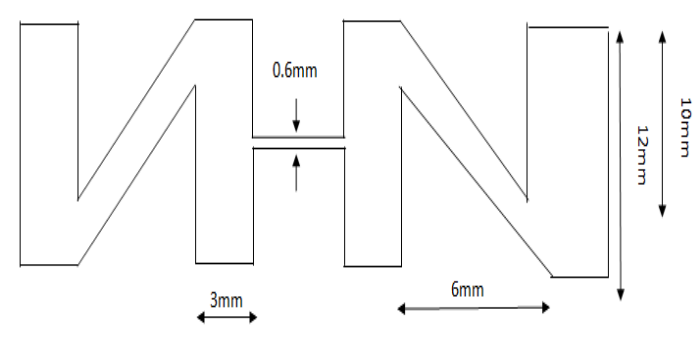

(a)

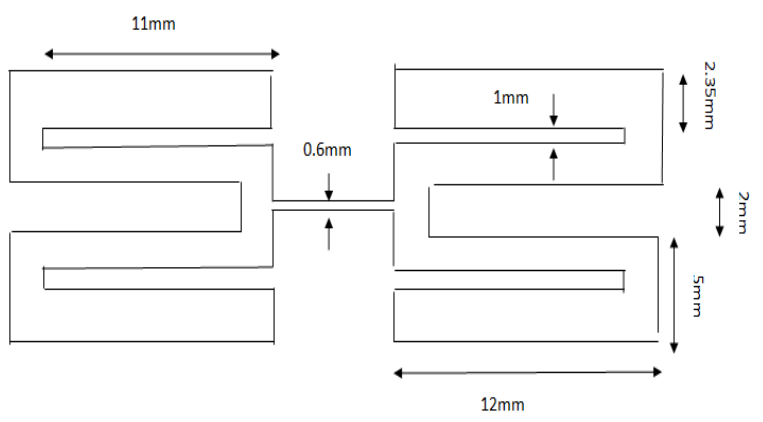

(b)

Fig: 4 Novel DGS shapes (a) N-shape DGS, (b) Meandershape DGS

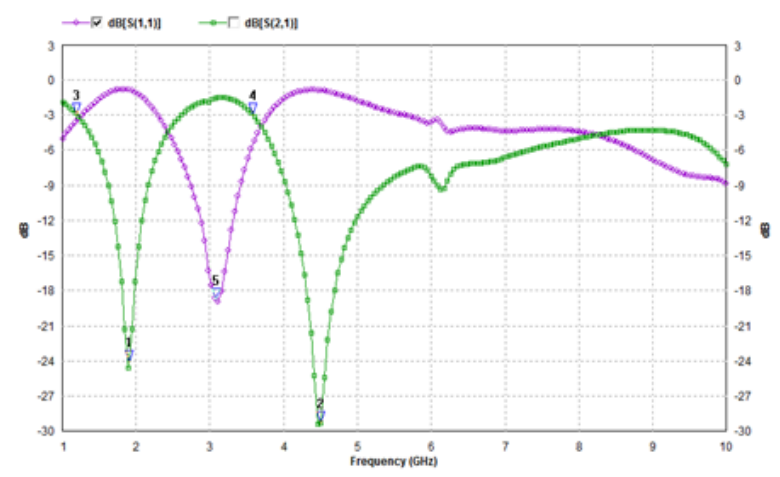

(a)

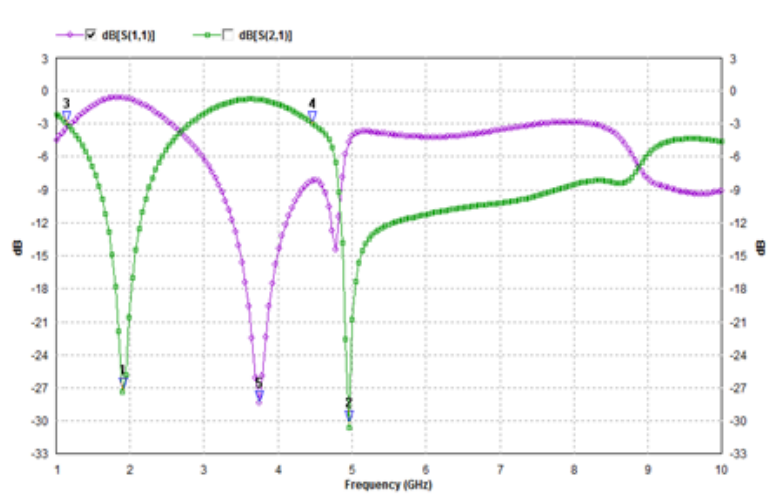

(b)

Fig: 5 Simulated frequency responses of novel DGS shapes (a) Frequency response of the $\mathrm{N}$-shape DGS, (b) Frequency response of the Meander-shape DGS 
The comparison between the novel DGS shapes and the published dumbbell DGS for the same etched area in the ground plane of the microstrip transmission line and by using the same substrate material is shown in Table 2. For the three shapes, it is found that the two novel DGS shapes provide a size reduction about $41 \%$ compared to the published dumbbell shape for the same attenuation pole location $\left(\mathrm{F}_{\mathrm{o}}=2.75 \mathrm{GHz}\right)$

Table 2. Comparison between the two novel DGS and the published dumbbell

\begin{tabular}{|c|c|c|c|}
\hline DGS & DGS & $\mathbf{F}_{\mathbf{o}}$ & $\mathbf{F}_{\mathbf{c}}$ \\
shape & photograph & (GHz) & (GHz) \\
\hline Dumbbell & & $\approx 2.75$ & $\approx 1.27$ \\
\hline N-shape & & $\approx 1.9$ & $\approx 1.2$ \\
\hline Meander & $\prod$ & $\approx 1.91$ & $\approx 1.14$ \\
\hline
\end{tabular}

\subsection{Circuit Model for the Proposed DGS \\ Shapes}

It is found that as shown in Fig.5, our novel DGS shapes have multi-stopband in frequencies so we use a general equivalent circuit model for DGS including multi-stopband in frequencies [13]. The proposed circuit model is shown in Fig.6 which consider the first and second resonance modes where $f_{01}$ and $f_{02}$ are the first and second resonant frequencies respectively, and $\mathrm{f}_{\mathrm{T}}$ denotes a transit frequency. Thus, a unit cell DGS, either in microstrip or CPW, is modeled by the two $\mathrm{LC}$ resonators, i.e., $\mathrm{L}_{1}$ and $\mathrm{C}_{1}, \mathrm{~L}_{2}$ and $\mathrm{C}_{2}$, in connection with a T-network consisting of $\mathrm{C}_{\mathrm{p}}, \mathrm{Ls}_{1}$, and $\mathrm{Ls}_{2}$. The T-network is essential here to represent the interaction between the two resonators. Below the transit frequency $f_{T}$ the first resonator dominates the frequency characteristics, whereas the second resonator is dominant for the frequency above $f_{T}$.

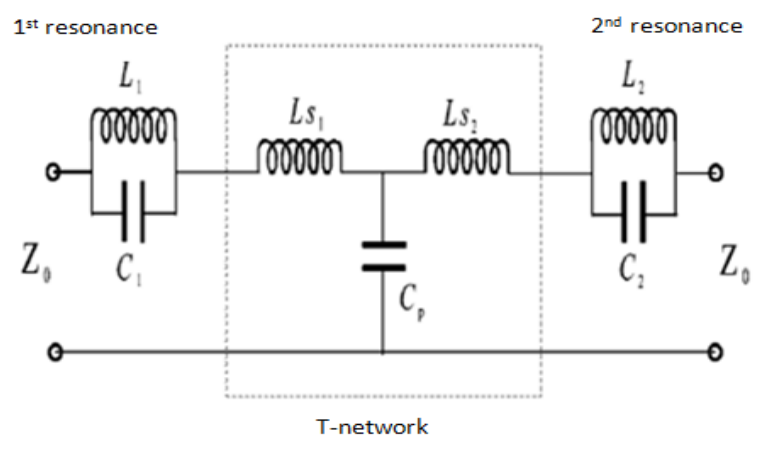

Fig: 6 General equivalent circuit model of DGS
The parameters of the equivalent circuit for novel DGS shapes (N-shape, Meander shape) are calculated by using eqs. $(3,4)$ and parameters extraction values are shown in Table 3 . Where $\mathrm{f}_{\mathrm{o} 1}=1.9 \mathrm{GHz}, \mathrm{f}_{\mathrm{o} 2}=4.5 \mathrm{GHz}, \mathrm{f}_{\mathrm{T}}=3.1 \mathrm{GHz}$ (for N-shape DGS) and $\mathrm{f}_{\mathrm{o} 1}=1.91 \mathrm{GHz}, \mathrm{f}_{\mathrm{o} 2}=5 \mathrm{GHz}, \mathrm{f}_{\mathrm{T}}=3.74 \mathrm{GHz}$ (for Meandershape DGS).

$$
\begin{gathered}
\mathrm{C}_{\mathrm{i}}=\frac{1}{\mathrm{Z}_{0}} \frac{1}{4 \pi \Delta \mathrm{f}_{3 \mathrm{~dB}_{-i}}}, \mathrm{~L}_{\mathrm{i}}=\frac{1}{\left(2 \pi \mathrm{f}_{0 \mathrm{i}}\right)^{2} \mathrm{C}_{\mathrm{i}}} \quad \text { For } \mathrm{i}=1,2 \\
\mathrm{Ls}_{\mathrm{i}}=\frac{\mathrm{X}_{\mathrm{ii}-\mathrm{X}_{21}}}{2 \pi \mathrm{f}_{\mathrm{T}}}+\frac{\mathrm{L}_{\mathrm{i}}}{\left(\frac{\left.\mathrm{f}_{\mathrm{T}}\right)^{2}-1}{\mathrm{f}_{\mathrm{oi}}}\right)} \text { For } \mathrm{i}=1,2, \\
\mathrm{C}_{\mathrm{p}}=-\frac{1}{2 \pi \mathrm{f}_{\mathrm{T}_{\mathrm{i} 1}}}
\end{gathered}
$$

Table 3. Parameters extraction for the novel DGS shapes

\begin{tabular}{|c|c|c|}
\hline $\begin{array}{c}\text { Parameters } \\
\text { extraction }\end{array}$ & N-shape & $\begin{array}{c}\text { Meander- } \\
\text { shape } \\
\text { DGS }\end{array}$ \\
\hline $\mathrm{C}_{1}(\mathrm{pF})$ & 1.33 & 1.4 \\
\hline $\mathrm{C}_{2}(\mathrm{pF})$ & 0.44 & 0.35 \\
\hline $\mathrm{L}_{1}(\mathrm{nH})$ & 5.3 & 5 \\
\hline $\mathrm{L}_{2}(\mathrm{nH})$ & 2.84 & 2.9 \\
\hline $\mathrm{Ls}_{1}(\mathrm{nH})$ & -1.6 & 0.062 \\
\hline $\mathrm{C}_{\mathrm{p}}(\mathrm{pF})$ & -0.88 & -0.83 \\
\hline $\mathrm{Ls}_{2}(\mathrm{nH})$ & -10 & -8.3 \\
\hline
\end{tabular}

\section{A NOVEL COMPACT SPIDER MICROSTRIP ANTENNA}

The proposed compact spider microstrip antenna is designed, simulated by using the ready-made software package ZelandIE3D to resonate at $4 \mathrm{G}$ by using FR-4 substrate with the following parameters; dielectric constant $\left(\varepsilon_{\mathrm{r}}=4.65\right)$, thickness $(\mathrm{h}=1.6 \mathrm{~mm})$, dielectric loss tangent $(\tan \delta=0.02)$. The compact spider microstrip antenna has a total area of $8.36 \lambda \mathrm{g}$ and shown in Fig.7. The simulation of the compact spider microstrip antenna is shown in Fig. 8 


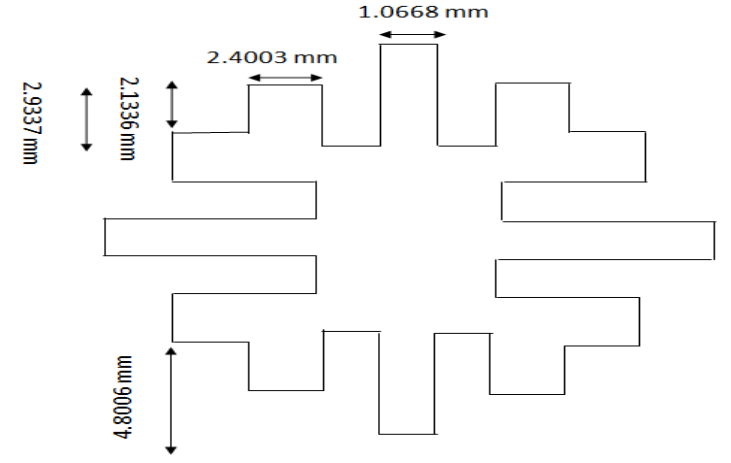

Fig: 7 Novel compact spider microstrip antenna

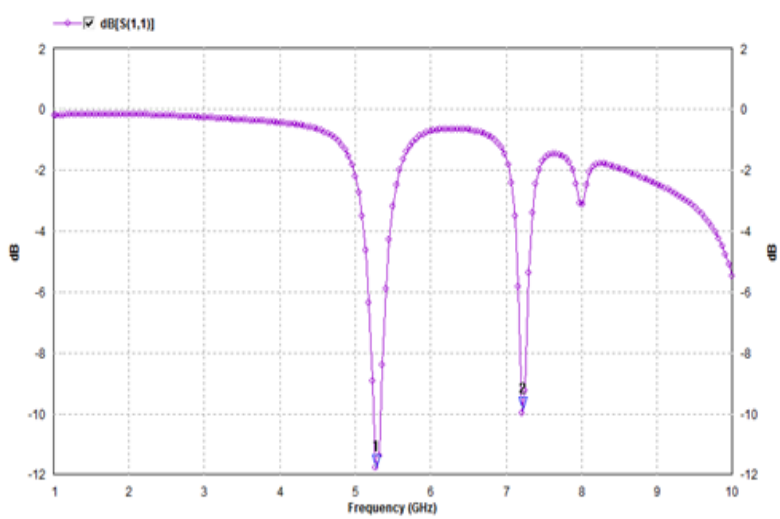

Fig: 8 Simulation result of reflection coefficient $\left(S_{11}\right)$ against resonance Frequency

\subsection{A Novel Compact Microstrip Antenna with Two Novel DGS}

Then we apply the two novel DGS shapes in the ground plane of the fabricated novel compact spider microstrip antenna in order to reduce its size as shown in Fig.9.

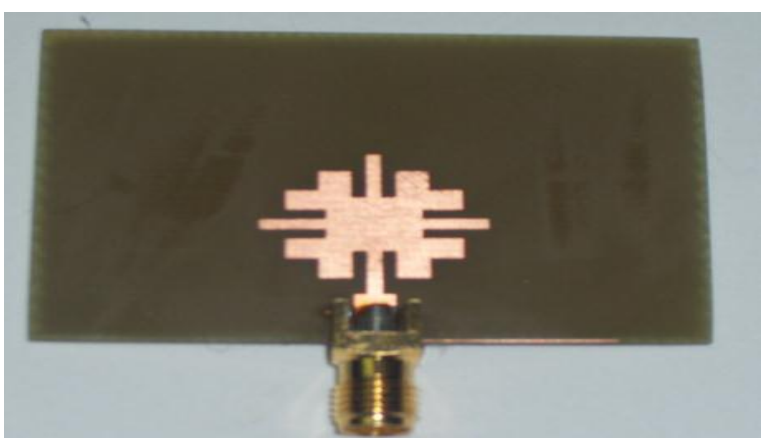

(a)Top View

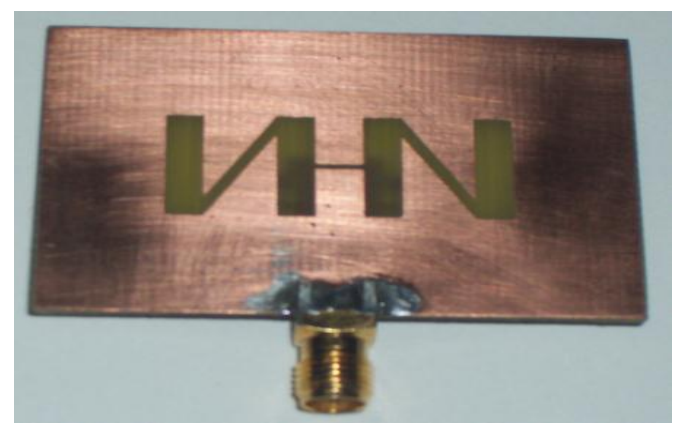

(b) Bottom View with N-DGS

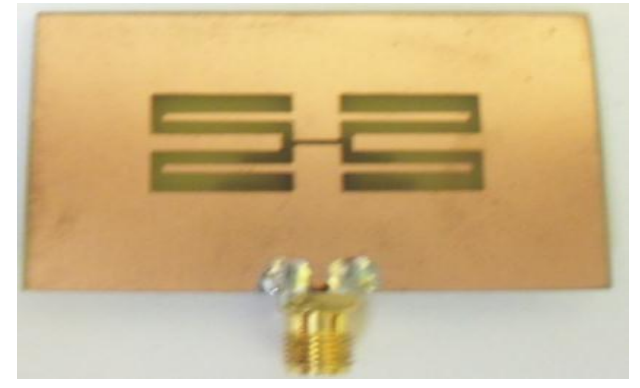

(c) Bottom View with Meander DGS

Fig: 9 Fabricated novel compact spider microstrip antenna with the two new DGS

\subsection{Measurement results}

The simulation and measurement results of the compact spider microstrip antenna with the N, Meander-DGS shapes are shown in Fig.10 ( $a, b$ respectively). Good agreements were found between the simulated and measurement results

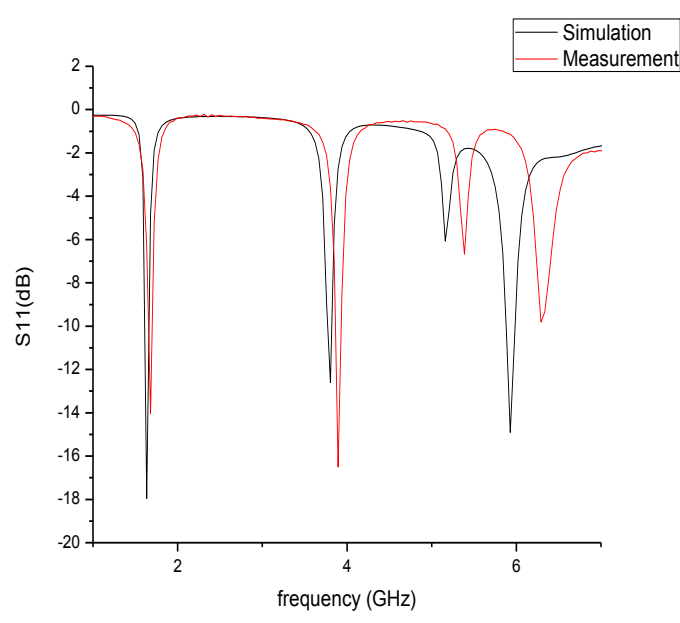

(a)

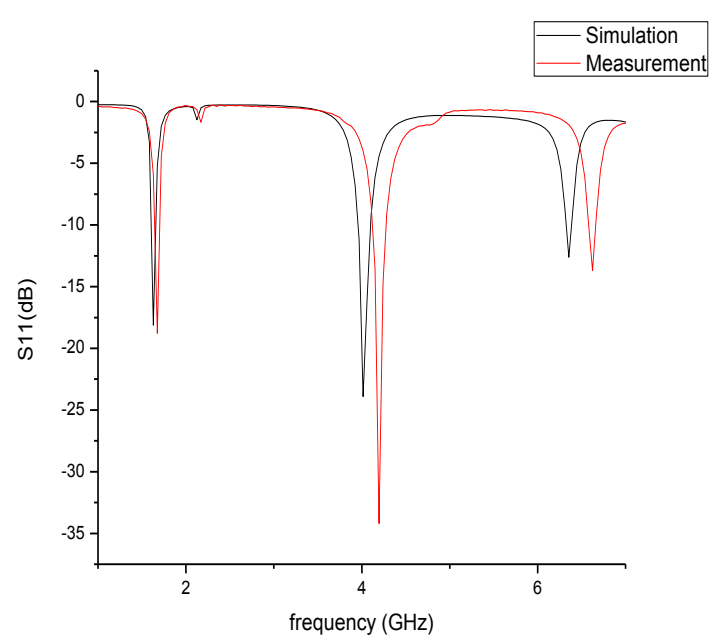

(b)

Fig: 10 Simulation and measurement results of the novel compact spider microstrip antenna (a) with $\mathrm{N}$-shape DGS,(b) with Meander-shape DGS 


\subsection{Tunable Compact Spider Microstrip Antenna}

In this section, we study the effect of compact spider microstrip antenna with vias inserted in different positions as shown in Fig11. Tables 4 discuss the simulated results.

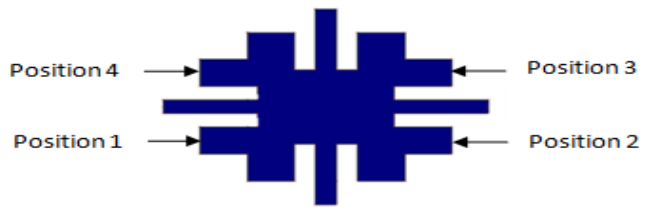

Fig.11 Different position of vias

Table 4.via with radius $r=0.5 \mathrm{~mm}$

\begin{tabular}{|c|c|}
\hline Via position & $\mathrm{F}_{\mathrm{o}}(\mathrm{GHz})$ \\
\hline 2 & $5.74,7.5,8.1$ \\
\hline 3 & $5,5.54,7.4$ \\
\hline $1 \& 2$ & $2.6,6.4,7.4$ \\
\hline $1 \& 3$ & $2.8,4.9,6.3,7.4,8$ \\
\hline $1 \& 4$ & $5.4,7.73,8.1$ \\
\hline $1 \& 2 \& 3$ & $3.3,6.5,7.5,7.73$ \\
\hline $1 \& 2 \& 3 \& 4$ & $4,6.5,7.6$ \\
\hline & \\
\hline
\end{tabular}

\subsection{Equivalent Circuit Model of Compact Microstrip Antenna with New N-Shaped DGS}

This section, describes the equivalent circuit model of the total structure (compact spider microstrip antenna with the new N-shaped DGS included coupling coefficients.. We will divide the estimated equivalent circuit model into three sections, the first section represents the equivalent circuit of compact spider microstrip antenna which represented by a resonant circuit with inductor $\left(\mathrm{L}_{\mathrm{a}}\right)$ in parallel with a capacitor $\left(\mathrm{C}_{\mathrm{a}}\right)$, the second section represents the $\mathrm{N}$-shaped DGS equivalent circuit which described in section 2-3 and the last section represents the coupling between the compact spider microstrip antenna in the top of the structure and the $\mathrm{N}$-shaped DGS in the bottom of the structure as shown in Fig.12. Let $\mathrm{L}_{\mathrm{k}}$ represents the magnetic coupling, while $C_{k}$ represents the electrical coupling. We will consider that the compact microstrip antenna is divided into two equal sections and placed between them the equivalent circuit of the N-shaped DGS and coupling circuit [14].By using the help of ready made software package, it is found that the imaginary part of impedance for S-parameters of the total structure at the first and second resonant frequencies are $\mathrm{J} 18 \Omega$ and $\mathrm{J} 16 \Omega$ respectively. We will calculate the corresponding imaginary part of the impedance for the simplified circuit model shown in Fig. 13, where $Z_{a 1}, Z_{a 2}$ represents the two equal section of the spider antenna at $5.28 \mathrm{GHz}$ which equal totally $\mathrm{J} 16.71 \Omega$ and $X_{C_{K}}, \quad X_{L_{k}}$ represents the reactance of $\mathrm{C}_{\mathrm{k}}$ and $\mathrm{L}_{\mathrm{k}}$ respectively at $1.63 \mathrm{GHz}$ and $3.8 \mathrm{GHz}, \mathrm{Z}_{\mathrm{DGS}}$ represents the imaginary part of the impedance for the $\mathrm{N}$-shaped DGS which equal $-\mathrm{J} 4.3 \Omega, \mathrm{J} 2.1 \Omega$ at $1.91 \mathrm{GHz}$ and $4.5 \mathrm{GHz}$ respectively. We will construct the two equations $(5,6)$ in order to find the two unknown values for $\mathrm{L}_{\mathrm{k}}$ and $\mathrm{C}_{\mathrm{k}}$.

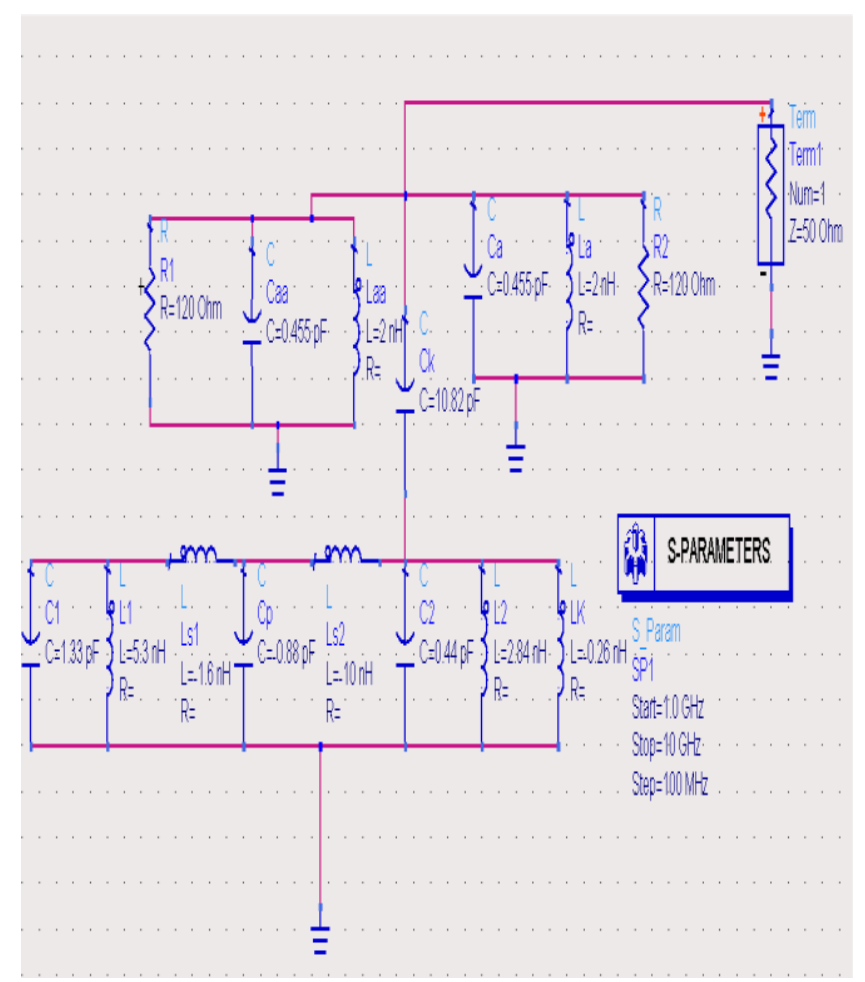

Fig.12 Equivalent circuit model of compact spider microstrip antenna with new N-shaped DGS

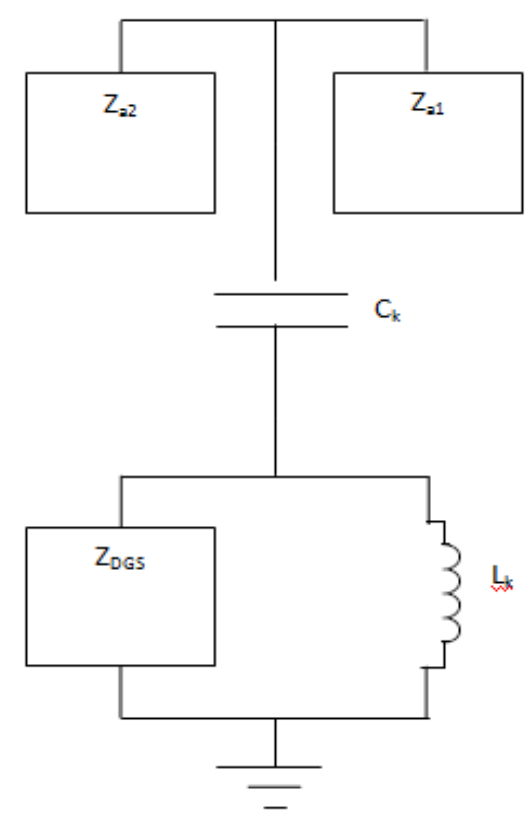

Fig.13The simplified circuit model for the total structure 


$$
\begin{gathered}
\mathrm{L}_{\mathrm{k}}=\frac{4.3+5.6 \omega_{01 \mathrm{C}_{\mathrm{k}}}}{\omega_{01+5.6} \omega_{01 \mathrm{C}_{\mathrm{k}}}^{2}} \\
L_{k}=\frac{-2.1+1.47 \omega_{02 C_{k}}}{\omega_{02-2.81} \omega_{02 C_{k}}^{2}}
\end{gathered}
$$

Solving the two equations, the values of the coupling coefficients are $\mathrm{C}_{\mathrm{k}}=10.82$ and $\mathrm{L}_{\mathrm{k}}=-0.26 \mathrm{nH}$.

By using the estimated values for the coupling coefficients the resonance frequency for the total structure as shown in Fig.14 is $1.7 \mathrm{GHz}$ which agree well the primary simulated results

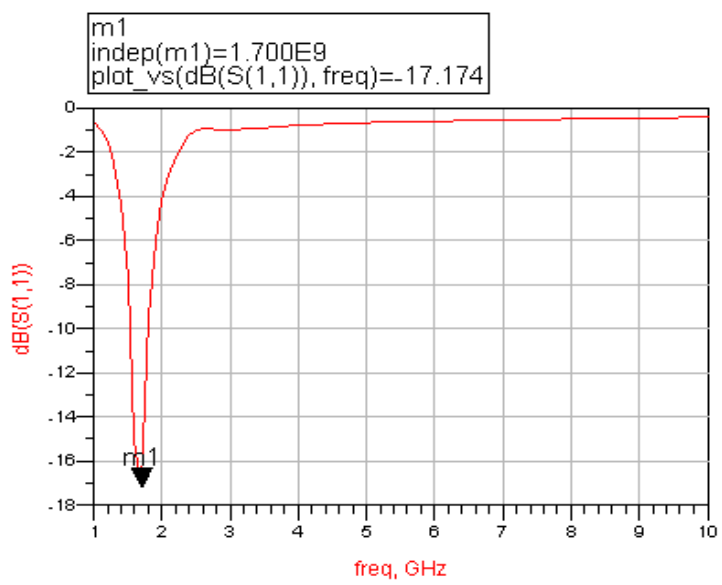

Fig.14 circuit simulation

\section{CONCLUSION}

In this paper, we firstly introduced two different new shapes of DGS which described their equivalent circuit model and parameters extraction. The two novel DGS shapes achieve a size reduction about $41 \%$ compared to the published dumbbell shape for the same attenuation pole location $\left(\mathrm{F}_{\mathrm{o}}\right)$ and provide two sharp stopband frequencies which are useful in the filter applications. Then we applied the new DGS shapes to minimize the size of a novel compact microstrip antenna to about 9 times compared to the conventional microstrip patch antenna resulting in a resonant frequency of $1.63 \mathrm{GHz}$. Secondly, we obtained negative values of equivalent circuit DGS lumped elements, represented by equivalent inductors and capacitors, which result in negative values for permittivity $(\varepsilon)$ and permeability $(\mu)$. In other words, development of a new technology that produces new materials which do not reflect the microwave frequencies (Meta Materials). Lumped element equivalent circuit models for single antenna and novel DGS shape have been proposed and also equation for the coupling coefficients is introduced.

\section{REFERENCES}

[1] F.Y. Zulkifli, E. T. Rahardjo, and D. Hartanto, "MUTUAL COUPLING REDUCTION USING DUMBBELL DEFECTED GROUND STRUCTURE FOR MULTIBAND MICROSTRIP ANTENNA ARRAY,' Progress In Electromagnetics Research Letters, Vol. 13, 29-40, 2010.

[2] Guha, D., S. Biswas, M. Biswas, and Y. M. M. Antar, "Concentric ring-shaped defected ground structure for microstrip application," IEEE Antennas and Wireless Propagat. Lett., Vol. 5, No. 1, 402-405, Dec. 2006.

[3] Guha, D., M. Biswas, and Y. M. M. Antar, "Microstrip patch antenna with defected ground structure for cross polarization suppression,"' IEEE Antennas and Wireless Propagat. Lett., Vol. 4, 455-458, 2005.

[4] Chung, Y., S. Jeon, D. Ahn, J. Choi, and T. Itoh, "High isolation dual polarized patch antenna using integrated defected ground structure," IEEE Microw. Component Lett., Vol. 14, 4-6, 2004.

[5] Liu, H., Z. Li, X. Sun, and J. Mao, "Harmonic suppression with photonic bandgap and defected ground structure for a microstrip patch antenna," IEEE Microw. and Wireless Components Lett., Vol. 15, 55-56, 2005.

[6] Salehi, M., A. Motevasselian, A. Tavakoli, and T. Heidari, "Mutual coupling reduction of microstrip antennas using defected ground structure," 10th IEEE International Conference on Communication Systems, 15, 2006 .

[7] Zainud-Deen, S. H., M. E. S. Badr, E. El-Deen, K. H Awadalla, and H. A. Sharshar, "Microstrip antenna with defected ground plane structure as a sensor for landmines detection," Progress In Electromagnetics research B, Vol. 4, 27-39, 2008.

[8] Zulkifli, F. Y., E. T. Rahardjo, and D. Hartanto, "Radiation properties enhancement of triangular patch microstrip antenna array using hexagonal defected ground structure,' Progress In Electromagnetic Research M, Vol. 5, 101-109, 2008.

[9] Dehdasht-Heydari, R. and M. Naser-Moghadasi, "Introduction of a novel technique for the reduction of cross polarization of rectangular microstrip patch antenna with elliptical DGS," Journal of Electromagnetic Waves and Applications, Vol. 22, No. 8-9, 1214-1222, 2008.

[10] Bi, D. H. and Z. Y. Yu, "Study of dual stopbands UWB antenna with U-slot and V-slot DGS," Journal of Electromagnetic Waves and Applications, Vol. 22, No. $17-18,2335-2346,2008$

[11] Debatosh Guha and Yahia M.M. Anter, Microstrip and Printed Antennas, New Trends, Techniques and Applications, 2011.

[12] Dal Ahn, Member, IEEE, Jun-Seok Park, Associate Member, IEEE, Chul-Soo Kim, Student Member, IEEE, Juno Kim, Student Member, IEEE, Yongxi Qian, Member IEEE, and Tatsuo Itoh, Life Fellow, IEEE, “ A Design of the Low-Pass Filter Using the Novel Microstrip Defected Ground Structure,' IEEE TRANSACTIONS ON MICORWAVE THEORY AND TECHNIQUES, VOL. 49, NO.1, JANUARY 2001.

[13] Jia-Sheng Hong, Senior Member, IEEE, and Bindu M Karyamapudi, "A General Circuit Model for Defected Ground Structures in Planar Transmission Lines,", IEEE MICROWAVE AND WIRELESS COMPONENTS LETTERS, VOL. 15, NO.10, OCTOBER 2005.

[14] Nardeen Tharwat Messiha, Atef M. Ghuniem, and Hadia M. EL-Hennawy," Numerical Investigation of Equivalent Circuit Models for Complementary OmegaLike Structures Loaded Microstrip Line', 978-1-42446051-9/11/\$26.00 (02011 IEEE 